Western University

Scholarship@Western

Aboriginal Policy Research Consortium International (APRCi)

8-15-2006

\title{
Aboriginal and Torres Strait Islander Suicide in Context
}

Ernest Hunter

University of Queensland

Helen Milroy

University of Western Australia

Follow this and additional works at: https://ir.lib.uwo.ca/aprci

Part of the Public Health Commons

Citation of this paper:

Hunter, Ernest and Milroy, Helen, "Aboriginal and Torres Strait Islander Suicide in Context" (2006). Aboriginal Policy Research Consortium International (APRCi). 435.

https://ir.lib.uwo.ca/aprci/435 
This article was downloaded by: [University of Western Ontario]

On: 16 December 2012, At: 07:02

Publisher: Routledge

Informa Ltd Registered in England and Wales Registered Number: 1072954 Registered office: Mortimer House, 37-41 Mortimer Street, London W1T 3J H, UK

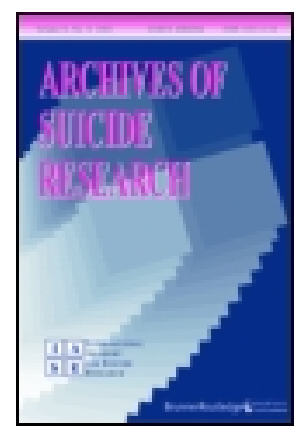

\title{
Archives of Suicide Research
}

Publication details, including instructions for authors and subscription information:

http:// www. tandfonline.com/loi/ usui20

\section{Aboriginal and Torres Strait Islander Suicide in Context}

\author{
Ernest Hunter ${ }^{a} \&$ Helen Milroy ${ }^{b}$ \\ a Queensland Health Psychiatry and North Queensland Health \\ Equalities Promotion Unit, University of Queensland, Cairns \\ ${ }^{b}$ Health Department of Psychiatry of Western Australia and \\ Centre for Aboriginal Medical and Dental Health, University of \\ Western, Australia \\ Version of record first published: 15 Aug 2006.
}

To cite this article: Ernest Hunter \& Helen Milroy (2006): Aboriginal and Torres Strait Islander Suicide in Context, Archives of Suicide Research, 10:2, 141-157

To link to this article: http:// dx.doi.org/ 10.1080/ 13811110600556889

\section{PLEASE SCROLL DOWN FOR ARTICLE}

Full terms and conditions of use: http://www.tandfonline.com/page/terms-andconditions

This article may be used for research, teaching, and private study purposes. Any substantial or systematic reproduction, redistribution, reselling, loan, sub-licensing, systematic supply, or distribution in any form to anyone is expressly forbidden.

The publisher does not give any warranty express or implied or make any representation that the contents will be complete or accurate or up to date. The accuracy of any instructions, formulae, and drug doses should be independently verified with primary sources. The publisher shall not be liable for any loss, actions, claims, proceedings, demand, or costs or damages whatsoever or howsoever caused arising directly or indirectly in connection with or arising out of the use of this material. 


\title{
Aboriginal and Torres Strait Islander Suicide in Context
}

\author{
Ernest Hunter and Helen Milroy
}

\begin{abstract}
Aboriginal and Torres Strait Islander suicide has been an issue of national public health and mental health concern for only one decade, having increased dramatically from levels that were very low in the late 1980s to levels of young adult male suicide that are now substantially higher than for the non-indigenous population. In this review the authors socially and historically contextualize these changes, identifying the causal frameworks adopted in developing interventions, and present an explanation in narrative and pictorial form that draws on critical family-centered trauma.
\end{abstract}

Keywords suicide, Aboriginal and Torres Strait Islander, young adult, Australia

From the information available, it is possible to construct a "typical" Indigenous case. For Far Northern Queensland region, it is a young Aboriginal male who has had a relative who has recently died by means of suicide. He is unemployed, or if employed, works part time on a CDEP project mainly involving manual labor. He has a history of heavy binge drinking and is intoxicated at the time of his death. He has either threatened or attempted to harm himself in the past. In the days or hours before the suicide some sort of interpersonal conflict occurred, either with members of his family or with his partner, either of apparent significance or what, to an outsider, might seem "trifling." The hanging, using material at hand such as rope or an electrical cord, takes place either in or close to his home, in a place visible to members of his family and possibly also to passers by (Hunter, Reser, Baird et al., 2001, p. 70).

The authors of this study emphasize that even for those suicides that conform to this scenario, this "typical" pattern says little if anything in terms of explaining an individual suicide and, furthermore, does not address the changing patterns that have been typical of indigenous Australia across both time and location. In this article we contextualize indigenous suicide and furthermore, describe changing patterns by exploring some explanatory frameworks.

\section{Social and Health Context}

Based on the 2001 census, the Australian Bureau of Statistics estimated the national Indigenous population at 460,140 , comprising $2.4 \%$ of all Australians: $90 \%$ identified as Aboriginal, $6 \%$ as Torres Strait Islander and the remainder as both. Some $40 \%$ of the Indigenous population are aged less than 15 years old compared to $21 \%$ of nonIndigenous Australians, with only $2.6 \%$ verses $12 \%$ being aged 65 years or older (Australian Bureau of Statistics, 2002). Death rates are elevated for almost all causes and 
are, overall, about four times higher than for non-Indigenous Australians. Quantifying burden of disease through disability-adjusted life-years (DALYs) in the Northern Territory (which with an Indigenous population of over 55,000 has the largest proportion of its population - approximately one third - of Indigenous descent) reveals that the Indigenous burden of disease is some 2.5 times greater than for non-Indigenous Territorians with the burden in the 35-54 year-age group being 4.1 times higher (Zhao, Guthridge, Magnus et al., 2004).

While the excess mortality and illhealth experienced by Aboriginal and Torres Strait Islander Australians reflects pervasive social disadvantage, it cannot solely be explained by socio-economic factors. Thus, while examinations of socio-economic disadvantage based on Census data according to location (SocioEconomic Indexes for Areas-SEIFA) for the 2001 census shows, not surprisingly, that Indigenous Queenslanders are concentrated in lower socio-economic areas of that state (Rawnsley \& Baker, 2004), further analysis of this data shows that, for Queensland as a whole the mortality rate ratio by SEIFA quintile increases in a linear fashion from 0.80 for those living in the least disadvantaged areas, to 1.23 for Queenslanders living in areas falling in the most disadvantaged quintile. The Indigenous rate ratio of 3.8 thus indicates mortality rates in excess of three times greater than for residents of those areas constituting the most disadvantaged quintile for the state (Kennedy, 2003).

Summarizing Indigenous health status in a "report card," the Australian Medical Association reported that the Indigenous infant mortality rate is two-and-a-half times that for the total population, babies are twice as likely to have low birth-weight, the gap between Indigenous and nonIndigenous life expectancy is some 20 years and median age at death is 25 years less than for non-Indigenous people (Ring \&
Brown, 2002). In addition to excess morbidity and mortality from most causes compared to non-Indigenous Australians, it has been known for some time that by comparison to the health disadvantages experienced by indigenous populations in other areas of "Anglo-settler colonialism" Australian Indigenous: non-Indigenous health differentials are higher (Kunitz, 1994; Kunitz, Streatfield, Santow et al., 1994). Furthermore, it has been clearly demonstrated that this situation is not improving (Lavoie, 2004; Ring \& Brown, 2003; Ring \& Firman, 1998). While data regarding Aboriginal and Torres Strait Islander mental health is limited, information from the Australian Institute of Health and Welfare for 1998 and 1999 reveals Indigenous: non-Indigenous standardized morbidity ratios based on hospital separation rates of 2.0 and 1.5 for Indigenous males and females respectively for all mental and behavioral disorders, 4.1 and 3.5 for mental disorders due to psychoactive substances, and 1.8 and 2.0 for schizophrenia and delusional disorders. Given issues of access, these figures almost certainly under-represent the excess burden of mental health disorders in Aboriginal and Torres Strait Islander Australia.

\section{Indigenous Self-Harm}

Australia's national suicide rate of 17.9 per 100,000 in 1999 sits in the middle to top third of countries monitored by WHO (World Health Organization), with rates hovering around those of Japan and Canada (Krug, Dahlberg, Mercy et al., 2002). While overall suicide rates have been remarkably steady in Australia since the 1920 s, the rates for young adults increased dramatically between the 1960s and 1990s with the increase largely accounted for by means of deaths by hanging among young males (Harrison, Moller, Bordeaux et al., 1997). 


\section{E. Hunter and H. Milroy}

Contemporary Aboriginal and Torres Strait Islander suicide must be further contextualized, most immediately within Indigenous patterns of harm from accidents, injuries and trauma. In 2002 the hospital separation rate for injury of Indigenous Australians was twice as high as for the non-Indigenous population (Australian Institute of Health and Welfare, 2003), with the largest single cause being assault. In that year the proportion of deaths, nationally, from accidents and injuries was almost three times greater for Indigenous $(16 \%)$ compared to nonIndigenous Australians (5.6\%) (Australian Bureau of Statistics, 2003). Among Indigenous Australians for the years 1999 to 2001 suicide was the most frequent cause of death from external causes accounting for one third of such deaths (Giskes, 2004). Because of significant problems associated with identifying and recording Indigenous status, determination of Indigenous suicide rates has been very difficult. However, analysis of deaths so identified for the period 1988 to 1998 for Western Australia, the Northern Territory and South Australia (jurisdictions with the most reliable data) demonstrated age standardized rates varying between 9.4 and $26.3 / 100,000$, giving an average standardized rate of 17.0 compared to 13.3/100,000 for non-Indigenous residents of these areas (Steenkamp \& Harrison, 2001). Compared to non-Indigenous deaths, Indigenous suicides for this period were concentrated in younger age-groups with the male-female ratio being 6.7:1. Hanging was the most common cause, accounting for two thirds of both Indigenous male and female deaths compared to $31 \%$ and $20 \%$ of non-Indigenous males and females respectively. For the state of Queensland, which for each year during the period 1998 to 2002 was ranked highest or second highest of all States and Territories in terms of the proportion of Indigenous deaths attributable to suicide (being about three times higher than the proportion for nonIndigenous Queenslanders), the rates for Indigenous males aged 15-24 and 25-34 were four and three times higher respectively than non-Indigenous Queenslanders of the same age (Giskes, 2004).

\section{Indigenous Suicide in a Historical Context}

The utilized statistics give no sense of temporal changes, with current rates increasing from rates of suicide three decades ago which were, at most, extremely low. While willed or self-willed death associated with sorcery or physical debility in traditional Indigenous societies might be considered a "suicide equivalent" phenomenon, it is in sharp contrast to the contemporary deaths by hanging of young men. Both, however, in different ways are meaningful, the former as a socially understood and affirmed consequence of behavior (transgression) or circumstance (debility), the latter as statement and communication that is meaningful in the particular intercultural political context of contemporary Australian society. Considering Indigenous suicide, thus, necessarily demands understanding the historical context in which this change is located.

However, not only has Australian Indigenous suicide varied with time, it is also unevenly distributed geographically. For instance, in the state of Queensland where the total number of Indigenous suicides increased nearly four fold in the period 1992 to 1996 (accounted for by an increase in young male hanging deaths), the far north, which contains approximately one half of the Indigenous people living in Queensland, accounted for 63\% of the Indigenous suicides through the late 1990 s. Furthermore, within that area suicides were concentrated within three communities constituting less than $20 \%$ of the region's Aboriginal and Torres Strait Islander population, accounting for $40 \%$ of the deaths by suicide. Additionally, these 
communities contributed to the excess of suicides at different times, suggesting an overlapping "wave" of suicides, implicating a condition of community risk varying by location and time (Hunter, Reser, Baird et al., 2001).

As noted previously, Indigenous suicide rates have been increasing from very low rates over the last several decades with the trend only recognized in the late 1980s. At that time suicides tended to occur in non-remote settings among non-traditional groups and were often associated with the acute effects of alcohol consumption and its consequences (Hunter, 1993). At the end of that decade a national inquiry, the Royal Commission into Aboriginal Deaths in Custody, was empowered to investigate Indigenous deaths in police and prison custody, a significant proportion (approximately one-third) of which resulted from suicide by hanging (Royal Commission into Aboriginal Deaths in Custody, 1991). The national media's focus on the Royal Commission provided for the development of political understandings of hanging that fore-grounded the effects of colonization and oppression, thus contributing to the contemporary "meaningfulness" of hanging by young Indigenous people whose manifest disadvantage by comparison to the wider society is often experienced as oppression and discrimination. Since the Commission, suicide has continued to increase in the wider Aboriginal and Torres Strait Islander population, with hanging being by far the most common method. Furthermore, no Indigenous settings are unaffected by the processes of social change, and while Indigenous suicide was initially located largely in areas of rapid change and inter-cultural pressures, it now appears to be generalizing and becoming more common in certain remote and "traditional" populations (Davidson, 2003), sometimes taking on "traditional" meanings (McCoy, 2004; Parker, 1999; Parker \& Ben-Tovim, 2002).

\author{
Explanatory Frames
}

While those taking their lives in the decade-and-a-half since the Royal Commission's investigation have most commonly been young men, the patterns continue to change. In the first months of 2004 four children aged 12 and 13 died as a result of hanging in four small communities of a remote area in one state. How does one frame such a constantly changing picture? One model draws on the impact of recent events on parenting and the consequences for the development of a coherent sense of self. According to this construction the rapid social transformations that occurred across Indigenous Australia from the late 1960 s, a period that has been described as "deregulation" (Hunter, 1999), most immediately and noticeably impacted young adults who suddenly experienced the lifting of onerous controls and access to a cash economy through welfare, including unrestricted access to alcohol. These "liberties" came at a cost; while race-based discriminatory legislation had been revoked, Indigenous Australians remained excluded from the ideals, resources and social advantages of the wider society by continuing denial of access to the means (education, economic, political...) necessary to realize those ideals, what Eugene Brody has referred to as "cultural exclusion" (Brody, 1966). The social and behavioral consequences quickly became evident. For instance, in the Kimberley region of Western Australia there was a dramatic increase in deaths from external causes (primarily accidents, motor vehicle accidents and homicide, largely being of young adults), from $2 \%$ to $4 \%$ of male and female deaths in the 15 years prior to 1971 , to $25 \%$ of male and $15 \%$ of female deaths in the 15 years following. Suicide, by contrast, did not begin its inexorable increase until the late 1980s-some 15 years delayed (there was one Indigenous suicide in the Kimberley in the 1960s, three in the 1970s, 21 in the 1980s, and 46 in the 
1990s). Those dying by suicide since the mid-1980s have been teenagers - the children of parents who experienced the rapid social transformations of deregulation as young adults (and new parents). They belong to the first generation in that region to have been raised, in some settings, in a world characterized by normative instability including substance use and its consequences. Not only are they at risk of self-harm but, to different degrees in different communities, also to petrol sniffing, chroming, sexual abuse (as victims and perpetrators) and selfdestructive confrontations with increasingly reactionary authorities.

Self-harm, in one manifestation or another, is no longer uncommon among Aboriginal and Torres Strait Islander young people. Given the visible nature of such behaviors-from children wandering the streets with cans of petrol, to violence to self and others, to threats and representations (both graffiti and visual arts) of suicide and, ultimately, to hanging and its aftermath-children are now exposed directly. Thus, it is noteworthy that among the four child deaths by hanging described earlier, three had had direct or indirect experience of suicide or suicidal behavior. They belong to the first generation whose early development has included exposure to the threat or act of self-annihilation.

\section{A Deeper Analysis}

Over the last decades there have been a range of analyses presented of Indigenous suicide in Australia including those foregrounding political context (Tatz, 1999, 2001), psychopathology (Parker, 1999; Parker \& Ben-Tovim, 2002), trans-generational trauma (Atkinson, 2002), psychocultural explanations (Reser, 1989, 1990), socio-historical factors (Hunter, 1993), public health perspectives (Hunter, Reser, Baird et al., 2001) and many others. While the framework presented previously is certainly more reflective of the complex interplay of factors informing Indigenous suicide than unidimensional causal analyses that assign responsibility to hopelessness, anomie, internalized rage or alcohol, it is still lacking. It identifies but does not explain the mechanisms underlying the vulnerability, particularly for young men, to behavioral disinhibition and disturbance during the period referred to earlier as deregulation, changes which have been so consequential for parenting and other social roles.

However, across this profusion of theories there are several points on which there is general agreement: 1) changes in the patterns of self-harm over time relate to social forces which are embedded in the historical experiences of Indigenous peoples; 2) Indigenous self-harm reflects individual vulnerability stemming from internal states informed by experience and circumstance; and 3) vulnerability is linked to developmental factors and, thus, to those historical forces that have impacted on the environment of family life. In the following section a narrative synthesis linking these factors is suggested.

\section{From Genocide to Self-Annihilation}

In traditional Indigenous societies, life was intimately connected to the environment and as such, all things were sacred. Life affirmed and celebrated creation with each person playing a valued and irreplaceable part in a much bigger story spanning the beginning of time to eternity, as suggested in an elder's comment:

In this way I learnt from my father all the important things I need to know about life, about our history, our customs and our ceremonies. When I lost my father I am the man responsible for keeping alive the songs and ceremonies and the stories and for 
passing them on when the time comes (Isaacs, 1995, p. 36).

Within this worldview there is no explanation for or expectation of selfannihilation. Rather, life entails obligation-to care for country and kin, live out one's purpose and continue the greater story. This is a perspective that has been reflected in key national reports which have supported a holistic view of life and culture, connection to country and the cyclical continuity of existence. In this view, health and well being are part of the "neverending" cycle of life (National Aboriginal Health Strategy Working Party, 1989; Swan \& Raphael, 1995). What, then, does it mean to end the story abruptly, deliberately and prematurely-before fulfilling one's responsibilities and destiny? Why does a commitment to life change to become an intention to die, and what is required to restore what was once a healthy, stable and sacred balance? How is the circle suggested by elder Vilma Webb's comments broken?

We're only here for a short amount of time to do what we've been put here to do, which is to look after our country. We're only a tool in the cycle of things. It takes two people to make a baby, and a baby is nurtured by the Mother until it is able to go out into the world and help and keep the balance of nature. It's a big cycle of living with the land, and then eventually going back to it and recreating something new... (McConchie, 2003, p. 71).

Breaking the circle creates a discontinuity, a violent rupturing of the generational cycle of creativity and stability. This violence, as with the various types of physical violence that have increased within Aboriginal and Torres Strait Islander Australia over the last decades, can only be understood in a wider and longer experience of intercultural violence from the time of colonial confrontation and conflict to the present (Hunter, 1991, 1993). The following analysis emphasizes the complex ways in which exposure to and experiences of physical and institutional violence of persons and peoples informed the construction of identity and propensity for violence to self and others.

\section{Violence in Historical Context}

The frontier conflict that swept across Australia left a trail of devastation and despair. While it is now thought that significant depopulation as a result of smallpox had preceded European settlement (Campbell, 2002) there was clearly no precedent for the onslaught that ensued and there could have been no understanding of violence at the level of what is now understood as genocide. Initial responses to this cataclysm would probably have included confident resistance rapidly giving way to desperate fight or flight and, ultimately, profound and numbing shock, traumatic stress engulfing clans, tribes and nations.

Regardless of the level of analysis, the most vulnerable within the changing social and family structures were children (Hunter, 1999). From infants' exposures to uncertainty and fear on their mothers' faces, to children witnessing indiscriminate violence and intentional massacre, the developmental effects were unavoidable. As was the case with child survivors of the Holocaust (Dwork, 1991), in response to trauma of such magnitude, some children would have survived by becoming silent and invisible, hiding from threat and learning to flee in the face of danger. Others may have allied themselves with the colonizers, seeking protection and identifying with the aggressor in order to survive. Some experiences would have been committed to painful memory, others lost or erased, some simply unutterable. 


\section{E. Hunter and H. Milroy}

What followed the physical violence was a period of "quiet" when, after the appropriation of land and resources, Aboriginal groups were institutionally contained and controlled by racist legislation supporting policies of isolation and segregation that ensured passivity. Powerlessness was assured by the convenient ambiguities of policy and process; Protector was the formal title usually conferred to those charged with responsibility for Aboriginal welfare and wellbeing - a role which too often was also policeman and prosecutor, rendering any sense of trust inconceivable in the blurring of protector and perpetrator.

One might wonder how anyone survived such sustained abuse, or that the wider society was unknowing. Despite what Stanner (1979) called "the great Australian silence," a "cult of disremembering" in the broad Australian psyche through the mid part of the last century and subsequent reflection on why we "weren't told" (Reynolds, 1999), it is abundantly clear that many people were, in fact, aware. It is hard to escape the conclusion that for Indigenous Australians this must surely have been experienced as indifference, and that what was felt to be at stake was survival itself. For many, to survive in the face of trauma across generations, including the forcible removal of children and repeated violations of self and family, demanded that feelings be repressed or dissociated, that the realities of exclusion be denied or distorted (living "as if" one was accepted as part of the wider Australian society), or simply finding the strength to endure with the hope that future generations would be spared the pain of those in the past and present.

During the decades of institutionalization and assimilation Aboriginal parents were powerless in the face of State control of family life; the State automatically assuming responsibilities at birth that denied parental rights and meant, in essence, that Indigenous babies were born into institutional captivity and, if not, were subject to being wrenched from their mother's care to be placed there 'for their own good'. The wider society was largely deaf to the cries of these children and it is probable that some infants would have withered and died in a state of anaclitic depression. Many children grew up nursing other children, adopting them as their own only to watch them suffer or be moved away. Only in the 1980s were there serious attempts to reconstitute shattered family relationships (Edwards \& Read, 1989; Read, 1981); only in the 1990s have the dimensions become evident (Haebich, 2000) and the processes of accountability belatedly begun (Human Rights and Equal Opportunity Commission, 1997).

With the rapid social changes from the 1970 s the numbing that previously supported survival lifted and long stifled emotions emerged, at times unregulated and overwhelming. As noted earlier, fuelled by unrestricted access to alcohol (and later other substances) the behavioral consequences included risk-taking, violence, and the undermining of capacity to address the responsibilities of family and community life. Increasingly, children's experience of families included the depression, fear and rage of parents and others. In this time of turmoil one might wonder how children could make sense of their world while their parents were struggling to come to terms with their own experiences. While now able to contemplate a future that was inconceivable for earlier generations, these parents were increasingly aware of the tragic legacies of the past, levels of loss and trauma that were profound and ongoing. The deliberate damage to Indigenous family and kinship structures created confusion, frustration and resentment compounded by deception and discrimination that persists. The harm to culture and the sanctity of life has devastated the purpose, volition and agency, critical to cultural continuity and integrity, resulting in a state of discontinuity and incoherence within a 
dominant society which remains invested in denial, rationalization and trivialization of past policies and practices (Hunter, 1996) and which still defines the values by which such injustices are considered and recompense in the present contemplated. While Indigenous children of earlier generations were often raised in situations where parents' rights were systematically violated, contemporary children confront a generation of parents amongst whom many have "gone missing" as new "freedoms" transformed into poverty, fragmented existence and cultural exclusion (Brody, 1966). Blame is conveniently apportioned (to the victims, Indigenous parents) and, ironically, rationalizes past racist legislation and practice.

The impact of the noted social forces have been uneven and informed by differences by population (Torres Strait Islander versus Aboriginal), location (urban, rural versus remote, or by State and Territory, each of which had different approaches to Indigenous affairs), history (for instance containment on missions or government reserves versus roles in the cattle industry) and other factors. However, consistent across all in relation to the perpetration of violence to self and significant others has been the vulnerability of young adult males. While such violence is almost entirely intra-culturally contained it can only be understood within a historical context that takes account of an inter-cultural context with traditional sacred and economic roles of Aboriginal men diminished (particularly on mission settlements), differentially blocked access to mainstream ideals for Aboriginal men (compared to women whose roles as mothers were valued and affirmed), inferred greater mainstream opprobrium to inter-racial relationships involving Aboriginal men (compared to Aboriginal women with European men) (Hunter, 1991), and in which Aboriginal men have been disempowered economically compared to women who have been "privileged" as "ideal welfare recipients" (Collman, 1988). These forces have influenced the structure of and roles within Indigenous families and have been consequential, particularly, in the construction of young male identity (Hunter, 1999). To this complex social-developmental arena must be added the influence of role-modeling in settings where male violence (to self and others) has increased dramatically and the implications in terms of bonding and stable attachment of women as victims to their male children. To the extent that these factors operate they would certainly increase the probability of difficulties for boys developing a stable, coherent and positive sense of self both as an Aboriginal male and as part of the wider Australian society.

So, how do contemporary Indigenous youth make sense of their existence, marginalized within an advantaged majority society that is increasingly reactionary in the face of world and domestic events? Many have moved from a path determined by sacred responsibilities to one as disrespectful of humanity as the colonizers were to generations of Aboriginal people. This behavior might be understood as a response to continued (but more subtle) oppression. It might also be understood as internalizing the oppressor-or simply the final stage of assimilation, taking on and amplifying some aspects of the dominant culture's way of coping with life's emptiness, despair or desire for control through alcohol and drug abuse, unfettered violence, child neglect-and suicide. Such youth grow up in communities in which death and disability are omnipresent-in ways of which most in mainstream Australia have no conception. When life appears uncontrollable, and early death is inevitable, how and when this occurs may be the only means of control left. Traditionally, the process of early autonomy for Aboriginal children facilitated the development of good adaptational and 


\section{E. Hunter and H. Milroy}

survival skills (Hamilton, 1981). It also contributed to the child's ability to make decisions, act independently and tolerate the burden of personal responsibility at a much younger age than would be expected for non-Indigenous children. When this exists within a guiding and nurturing society, the child's developmental ability may be enhanced. However, when those with responsibilities for guiding and nurturing have gone missing the potential for developmental disarray and self-destruction is heightened.

This may be particularly relevant for those at greatest risk of suicide-young men. It has been suggested in relation to a remote, tradition-oriented population, that this group is vulnerable to intergenerational disruption of the critical social 'holding' processes that inform and make safe individuation and transition to adulthood (McCoy, 2004). In the face of this disruption and its attendant isolation, suicide can become: "not the ultimate expression of control over one's body, but the embodiment of social and painful disconnection from others. This experience, I suggest, can only be described as intragenerational trauma” (p. 229).

\section{Intervening Mechanisms}

The effects of chronic stress on brain development and function are well known (Schore, 1994) including the neurobiological consequences of relational trauma for attachment problems and a predisposition to violence (Schore, 2003). Sustained levels of cortisol can cause permanent damage to areas of the hippocampus involved with memory, and chronic stimulation of the hypothalamic-pituitary-adrenal axis can lead to permanent changes in function. Work in remote Aboriginal communities has demonstrated high levels of corticosteriods and catecholamines associated with the social periodicity of welfare dependence (Schmitt, Harrison, Spargo et al.,
1995, 1998). What, then, of the impact of two hundred years of chronic stress combined with present trauma and loss, chronic illness, acculturation and discrimination? It is now clear that second-generation effects of trauma experienced by parents can significantly impact the development of their children (Hesse, Main, Abrams et al., 2003), with reciprocal and mutually reinforcing consequences for both parent and child.

We have not herein addressed the additional risks to neurodevelopment of exposure to alcohol during pregnancy but it is known that this increases the risk of subsequent impulsive behavior and is also known that the rates of fetal alcohol syndrome in its full expression are substantially higher in the Aboriginal than in the wider Australian population, in Western Australia by at least a factor of 50 (Bhatia \& Anderson, 1995).

Findings from the Western Australian Aboriginal Child Health Survey, the largest population survey of Indigenous physical, social and emotional health yet undertaken (Zubrick, Lawrence, Sillburn et al., 2004) reveal that $23 \%$ of women acknowledged drinking during pregnancy and $49 \%$ use of tobacco (compared to $22 \%$ in the general population). Premature birth and low birth-weight are common, with the state of developmental risk compounded by high rates of childhood infections, including recurrent chest $(12 \%)$, skin $(8 \%)$, gastrointestinal $(6 \%)$, and ear infections $(18 \%)$. This survey also demonstrated a range of social and health factors impacting educational and employment outcomes, and loss of fluency in Aboriginal language, particularly in metropolitan areas. Furthermore, of the children surveyed, $41 \%$ lived in households affected by the forcible removal or relocation of the primary or secondary caregiver or grandparent and $20 \%$ of teenagers were being cared for by someone other than their parents. Suffice it to say that these familial, experiential, relational, and neurobiological factors 
complexly interact and amplify risk. However, while individual risk factors for deliberate self harm may be easy to identity in retrospect, the level of pervasive risk or the state of risk (Hunter, Reser, Baird et al., 2001) within the population group must be appreciated in order to understand the sometimes minor provocation that tips the balance for self-harming behavior. We need a deeper understanding of Indigenous suicide beyond preoccupation with the “tipping point” (Goldney, 1998).

\section{Synthesis}

The central issue for Aboriginal peoples since colonization has been the right to exist, freely and humanly, and to sustain the continuity of existence as Aboriginal peoples. This remains under threat. Considering life as a narrative or story, the desire to end one's personal story abruptly, prematurely and deliberately can be seen to stem from the complex interplay of historical, political, social, circumstantial, psychological, and biological factors that have already disrupted sacred and cultural continuity; disconnecting the individual from the earth, the universe and the spiritual realm-disconnecting the individual from the life-affirming stories that are central to cultural resilience and continuity. Children of all cultures grow up learning about their place in their world through hearing stories, directly or vicariously, about themselves, their family, their community and culture. This is an essential part of healthy development and helps the children learn to value themselves and others through the value placed on them by those they value. For Aboriginal children in settings of turmoil this fundamental experience may be compromised and their story may be fragmented-or lost. Perhaps the ultimate damage is to the coherence and continuity of the story in the face of personal loss, confusion and alienation. Perhaps the ultimate control sought is, paradoxically, over when their participation in this story ends, making sense of that which may have seemed senseless. When life is experienced as intolerable, when connections are severed, when it seems that society views you as useless, when the only way to feel good is to be high and the only way to escape is to remain intoxicated, when friends and loved ones are dying and there is no expectation of living to middle age, when power is expressed through violence, when hope is lost and no one hears you cry-perhaps someone will shed tears at your funeral. Perhaps suicide is an irrational and impulsive act, without rhyme or reason. Perhaps it is the culmination of existential despair that has no solution other than to return to an earlier state of being. Perhaps self-annihilation is genocide by proxy (this was explicitly suggested in a cartoon in the Sydney Morning Herald in 1987 titled "Progress" with the first panel being of an Aborigine shot by a settler in 1877, the last being of an Aborigine hanged by a noose suspended from prison bars while a European stands by commenting "Look, no hands!")

\section{RESPONSES}

With Indigenous suicide being a recent phenomenon, responses to Aboriginal and Torres Strait Islander self-harming behavior have only been emerging since the mid-1990s which coincided with the development of a national strategy for suicide prevention, the LIFE (Living Is For Everyone) framework (Commonwealth Department of Health and Aged Care, 2000a; Mitchell, 2000). This has built on a broader approach to mental health within the National Action Plan for Promotion, Prevention and Early Intervention for Mental Health (Commonwealth Department of Health and Aged Care, 2000b) that itself draws on the Mrazek and Haggerty (1994) spectrum of mental health interventions. 


\section{E. Hunter and H. Milroy}

Over this decade there has been a shift nationally from problem-specific policies and strategies (homelessness, violence, suicide...) to more broadly addressing the developmental and social factors that inform risk for adverse behavioral outcomes more generally, and within the specific area of suicide from crisis-response to prevention. In the Indigenous arena reports and strategies relating to substance misuse, child abuse, child sexual abuse, youth crime, family violence, youth suicide, and social and emotional well being have been produced over the last decade. The shift towards a more integrated approach to addressing early developmental and social determinants of risk has lagged behind the mainstream. At present, crisisresponse initiatives such as developing "community gatekeepers" (Capp, Deane, Lambert et al., 2001) remain the most common approach. There are also attempts to develop an evidenced-based framework for Indigenous suicide prevention (Delaney Raphael, Wooding, 2003) and culturally informed screening tools (Westerman, 2003). By and large these remain focused at the "tipping point."

Following the Royal Commission into Aboriginal Deaths in Custody and the attention that the Commission brought to Indigenous suicide, a group of Indigenous and mainstream groups in South Australia collaborated in developing an approach to counseling based on narrative therapy (Aboriginal Health Council of South Australia, 1995). An underlying principle of the project emphasized: "The grief experienced by Aboriginal families cannot be understood or addressed without an acknowledgement of the extraordinary injustices to which Aboriginal people have been subjected, and which they continue to live with in their day-to-day lives" (p. 3). Narrative approaches have since been enthusiastically embraced, primarily through non-mainstream Aboriginal organizations and services. Indigenous creativity in the performing and visual arts has also been harnessed to facilitate healing through the narrative process. The accompanying painting (Figure 1) was created and is used by one of the authors of this paper, Aboriginal child psychiatrist Helen Milroy, to explain and facilitate healing through personal and collective stories. The accompanying narrative is as follows:

We are part of the dreaming. We have been in the dreaming for a long time before we are born on this earth and we will return to this vast landscape at the end of our days. It provides for us during our time on earth, a place to heal, to restore purpose and hope, and continue our destiny.

Our country and people have suffered many traumas since colonization, the magnitude of which is beyond words. Looking through trauma is like being trapped in the back of a mirror, there is no reflection of self. It is like being trapped in darkness, unable to see where to go or what is there, surrounded by 'not knowing', paralyzed by fear.

When we are wounded, our story is disrupted and life becomes fragmented. We may not be able to find our way forward and may start to see life through warped mirrors. We have to understand that trauma is only a part of our story and our story is part of a much greater story that has a different beginning, is enduring and will continue well beyond our lifetime.

To have integrity of existence we need to have an integrated experience throughout, so that we do not isolate pockets of our life, disconnected from present reality, and so that we do not live in two worlds but can maintain an essence of continuity throughout our existence on this earth. We cannot play parts without understanding the whole story of Australia. 


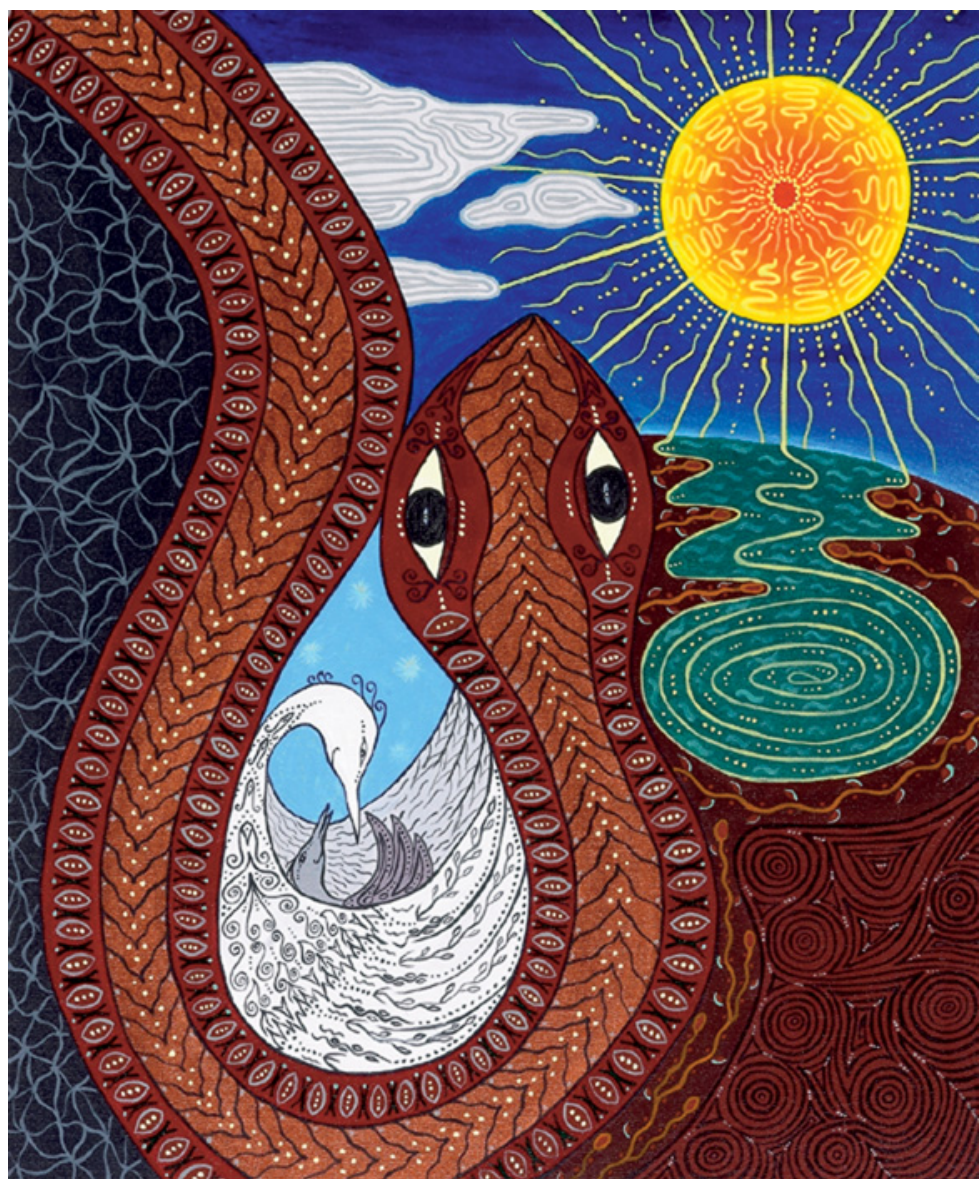

FIGURE 1.

Part of the problem in healing is being able to put all the parts together again as there are still too many of us missing. To survive as peoples distinct in culture, we have to restore the collective. The individual may not be able to carry the survival of the culture into eternity but the collective can.

We can return to the dreaming to heal, to rest for a while and have our spirit restored, to find our place on the serpent and recover our purpose in this life. We have to trust that we will be cared for until we can walk again, taking sustenance from the tree of life that has sustained us over generations. Our ancestors watch and wait patiently for our return. They are like the clouds that roll through the sky coming to greet us and shed tears for our wounds, holding us within a teardrop, soothed and bathed in this healing water.

Then a new day will dawn and our ancestral guides will once again set us on our journey through life. To recover, we have to allow the sun to shed light and warmth on dark places and assist our wounds to heal. 


\section{E. Hunter and H. Milroy}

We have to shatter these warped mirrors and find our true reflection of self, spirit and country. We have to stand together, united and proud. We may not always have control over what happens to us in life, but we do have control over truth. The ultimate control we have is the coherence and continuity of our own story.

To live without spirit is to sleep without dreams and wake to oblivion.

Drawing on individual and group empowerment through narrative approaches, and in line with the broader conception of individuals and communities at risk, emphasis has shifted to developing means to operationalize concepts of 'empowerment' in Indigenous families and communities (Tsey, Deemal, Whiteside et al., 2003) with adaptations to specific target groups, such as young men (Tsey, Patterson, Whiteside et al., 2004). Of course there is a contradiction implicit in project and program based solutions (to Indigenous health and social problems more generally as well as to suicide specifically) and critics have pointed out that replacing or undermining Indigenous cultural capabilities and responsibilities can, ultimately, be disempowering (Trudgen, 2000). Consistent with this thinking, certain key Indigenous intellectuals have proposed and initiated social entrepreneurial and other approaches to allow Indigenous peoples to free themselves of "passive welfare dependence" and the reliance on externally provided social services and programs as solutions to problems ultimately caused by those who seek to solve them (Pearson, 2000).

\section{DIRECTIONS}

These are matters that will require entire government support and are far beyond the resources or responsibilities of the health sector alone. Regardless, it is critical that those within that sector are not paralyzed into inaction by the enormity of the social change demanded, but continue to address those parts of the big picture that lie within their province-in "modest but practical ways" (Syme, 1997). This includes confronting institutional racism in the Australian healthcare system (Henry, Houston, Mooney et al., 2004). Specifically, addressing Indigenous suicide will require developing evaluation-proven models of intervention across sectors and levels of activity. This in turn demands shifting the focus of research towards solution-focused action research that prioritizes not only Indigenous needs but Indigenous research agendas (Hunter, 2001). This should take seriously the process and ethical considerations of such work, and the ways in which individual research contributes to a more strategic and integrated approach to Indigenous health research and health improvements (Humphery, 2001). In relation to specific research, the most pressing need is for a coordinated and comprehensive research strategy in this area that goes beyond description to identifying and defining the key determinants of risk status at a group level, as has been undertaken by Chandler, Lalonde, and Sokol (2003) from British Columbia. However, ultimately, real progress in this area will hinge on such insights informing meaningful and empowering change occurring in Aboriginal and Torres Strait Islander families and the children nurtured within them. We conclude with the words of Winston Seaton, an Aboriginal resident of Palm Island off the coast of Queensland, who in the late 1990s touched on the complex interaction of predisposing factors leading, ultimately, to selfannihilation:

What is tormenting the youth of Palm?

A question that's been asked from Butler Bay to Farm. 
Is it society or is it alcohol and dope, maybe no job?

That's when they think there's no hope.

Could it be so much pressure building up inside...

The young mind thinking perhaps there's nowhere to hide.

Maybe a drink will solve the pain, and a smoke to calm the brain.

One thing leads to another, arguing with family,

Your father and mother. Run and hide and let out the tears,

The pain is there but not the fears.

Is it some force that's taking them away,

Or pressure of society from living day to day?

No one knows what's in another's mind,

When a psychiatrist will try to seek and find.

Nothing works and nothing ever will,

Its over... its gone over the hill.

It's slowly tearing the mind apart, heart.

From head to toe then finally the

Talking to someone but they just won't listen.

Life is full of hits and misses.

Finally it's back to the drink and smoke

Where it all ends at the end of a rope.

\section{AUTHOR NOTE}

Ernest Hunter, Queensland Health Psychiatry and North Queensland Health Equalities Promotion Unit, University of Queensland, Cairns

Helen Milroy, Health Department of Psychiatry of Western Australia and Centre for Aboriginal Medical and Dental Health, University of Western, Australia
Correspondence concerning this article should be addressed to Ernest Hunter, NQHEPU, P.O. Box 1103, Cairns, Queensland, 4870, Australia, E-mail: ErnestHunter@health.qld.gov.au

\section{REFERENCES}

Aboriginal Health Council of South Australia (1995). Reclaiming our stories, reclaiming our lives: An initiative of the aboriginal health council of South Australia. Dulwich Centre Newsletter, 1, $1-40$.

Atkinson, J. (2002). Trauma trails, recreating song lines: The trans-generational effects of trauma in Indigenous Australia. Melbourne: Spinifex.

Australian Bureau of Statistics (2002). Population distribution, Aboriginal and Torres Strait Islander Australians, 2001 (Cat No. 4705.0). Canberra: Australian Bureau of Statistics.

Australian Bureau of Statistics (2003). Causes of death 2002 (Cat. N0. 3303.0). Canberra: Australian Bureau of Statistics.

Australian Institute of Health and Welfare (2003). Australian bospital statistics 2001-02 (AIHW Cat. No. HSE-20). Canberra: Australian Institute of Health and Welfare.

Bhatia, K. \& Anderson, P. (1995). An overview of Aboriginal and Torres Strait Islander health: Present status and future trends. Canberra: Australian Institute of Health and Welfare.

Brody, E. B. (1966). Cultural exclusion, character and illness. American Journal of Psycbiatry, 122(8), 852-858.

Campbell, J. (2002). Invisible invaders: Smallpox and other diseases in Aboriginal Australia 1780-1880. Melbourne: Melbourne University Press.

Capp, K., Deane, F. P., \& Lambert, G. (2001). Suicide prevention in Aboriginal communities: Application of community gatekeeper training. Australian and New Zealand Journal of Public Health 25(4), 315-321.

Chandler, M. J., Lalonde, C. E., \& Sokol, B. W. (2003). Personal persistence, identity development, and suicide: A study of Native and Non-native North American adolescents. Monographs of the Society for Research in Child Development, 68(2), 1-138.

Collman, J. (1988). Fringe-dwellers and welfare: The aboriginal response to bureaucracy. St Lucia: University of Queensland Press. 


\section{E. Hunter and H. Milroy}

Commonwealth Department of Health and Aged Care (2000a). Living is for everyone: A framework for prevention of suicide and self-harm in Australia. Canberra: Commonwealth Department of Health and Aged Care.

Commonwealth Department of Health and Aged Care (2000b). National action plan for promotion, prevention and early intervention in mental health. Canberra: Mental Health and Special Programs Branch, Commonwealth Department of Health and Aged Care.

Davidson, J. A. (2003). Presentation of near-hanging to an emergency department in the Northern Territory. Emergency Medicine (Fremantle), 15(1), 28-31.

Delaney, P., Raphael, B., \& Wooding, R. (2003). Suicide and self-harm aboriginal primary health care: An evidence based approach. In S. Couzos \& R. Murray (Eds.), Aboriginal primary health care: An evidence based approach (2nd Ed.) (pp. 617-630). Melbourne: Oxford University Press.

Dwork, D. (1991). Children with a star: Jewish youth in Nazi Europe. New Haven: Yale University Press.

Edwards, C. \& Read, A. (1989). The lost children: Thirteen Australians taken from their aboriginal families tell of the struggle to find their natural parents. Sydney: Doubleday.

Giskes, R. (2004). Suicide in Queensland: An update on recent trends and strategies. Research Brief No. 2004/08. Brisbane: Queensland Parliamentary Library.

Goldney, R. (1998). Variation in suicide rates: The "tipping point". Crisis, 19(3), 136-138.

Haebich, A. (2000). Broken circles: Fragmenting Indigenous families 1800-2000. Fremantle: Fremantle Arts Centre Press.

Hamilton, A. (1981). Nature and nurture: Aboriginal child-rearing in north-central Arnhem Land. Canberra: Australian Institute of Aboriginal Studies.

Harrison, J., Moller, J., \& Bordeaux, S. (1997). Youth suicide and self-injury Australia. Australian Injury Prevention Bulletin 15(March (Supplement)).

Henry, B. R., Houston, S., \& Mooney, G. H. (2004). Institutional racism in Australian healthcare: A plea for decency. Medical Journal of Australia, 180, 517-520.

Hesse, E., Main, M., \& Abrams, K. W. et al., (2003). Unresolved states regarding loss or abuse can have "second-generation" effects: Disorganization, role inversion, and frightening ideation in the offspring of traumatized, non-maltreating parents. In M. F. Solomon \& D. J. Siegel (Eds.), Healing trauma: Attachment, mind, body, brain (pp. 57-106). New York: WW Norton.
Human Rights and Equal Opportunity Commission (1997). Bringing them home: Report of the National Inquiry nto the Separation of Aboriginal and Torres Strait Islander children from their families. Canberra: Australian Government Publishing Service.

Humphery, K. (2001). Dirty questions: Indigenous health and 'Western research'. Australian and New Zealand Journal of Public Health, 25(3), 197-202.

Hunter, E. (1991). The inter-cultural and sociohistorical context of Aboriginal personal violence in remote Australia. Australian Psychologist, 26(2), 89-98.

Hunter, E. (1993). Aboriginal health and history: Power and prejudice in remote Australia. Cambridge: New York, Cambridge University Press.

Hunter, E. (1996). Denial, rationalization and trivialization of state intrusion into Aboriginal family life. Family Matters, 44(2), 16-19.

Hunter, E. (1999). Considering the changing environment of Indigenous child development. Australasian Psychiatry, 7(3), 137-140.

Hunter, E. (2001). A brief historical background to health research in Indigenous communities. Aboriginal and Islander Health Worker Journal, 25(1), 6-8.

Hunter, E., J. Reser, J., \& Baird, M. et al. (2001). An analysis of suicide in Indigenous communities of North Queensland: The bistorical, cultural and symbolic landscape. Canberra: Commonwealth Department of Health and Aged Care.

Isaacs, J. (1995). Wandjuk Marika life story. Brisbane: University of Queensland Press.

Kennedy, B. (2003). Indigenous SEIFA scores. Brisbane: Strategic Partnerships Office, Department of Aboriginal and Torres Strait Islander Policy.

Krug, E., L., Dahlberg, L. L., \& Mercy, J. A., et al. (2002). World report on violence and health. Geneva: World Health Organization.

Kunitz, S. (1994). Disease and social diversity: The european impact on the health of non-Europeans. New York: Oxford.

Kunitz, S. J., Streatfield, R., \& Santow, G. et al. (1994). Health of populations in northern Queensland aboriginal communities: change and continuity. Human Biology, 66(5), 917-943.

Lavoie, J. (2004). Governed by contracts: The development of indigenous primary health services in Canada, Australia and New Zealand. Journal of Aboriginal Health, January, 6-22.

McConchie, P. (Ed.) (2003). Elders: Wisdom from Australian Indigenous leaders. Melbourne: Cambridge University Press.

McCoy, B. F. (2004). Kanyirninpa: Health, masculinity and wellbeing of desert Aboriginal men. 
PhD dissertation. Centre for the Study of Health and Society, School of Population Health, The University of Melbourne.

Mitchell, P. (2000). Valuing young lives: Evaluation of the national youth suicide prevention strategy. Melbourne: Australian Institute of Family Studies.

Mrazek, P. J. \& Haggerty, R. J. (Eds.) (1994). Reducing the risk for mental disorders: Frontiers for preventive intervention research. Washington: National Academy Press.

National Aboriginal Health Strategy Working Party (1989). A national Aboriginal health strategy. Canberra: Department of Aboriginal Affairs.

Parker, R. (1999). An audit of coronial records for the "Top End" of the Northern Territory comparing factors in Aboriginal suicide against other suicides in the region. Unpublished dissertation. Royal Australian and New Zealand College of Psychiatrists. Melbourne.

Parker, R. \& Ben-Tovim, D. I. (2002). A study of factors affecting suicide in aboriginal and 'other' populations in the top end of the northern territory through an audit of coronial records. Australian and New Zealand Journal of Psychiatry, 36(3), 404-410.

Pearson, N. (2000). Our right to take responsibility. Cairns: Noel Pearson and Associates.

Rawnsley, T. \& Baker, J. (2004). Indigenous SEIFA for Queensland. Report prepared for: Office of Economic and Statistical Research. Canberra: Analysis Branch, Methodology Division, Australian Bureau of Statistics.

Read, P. (1981). The stolen generations: The removal of aboriginal children in New South Wales 18831969. Occasional paper No 1. Sydney: Ministry of Aboriginal Affairs.

Reser, J. (1989). Australian Aboriginal suicide deaths in custody: Cultural context and cluster evidence. Australian Psychologist, 24(3), 325-334.

Reser, J. (1990). The cultural context of Aboriginal suicide: Myths meanings and critical analysis. Oceania, 61(2), 177-184.

Reynolds, H. (1999). Why weren't we told: A personal search for the truth about our history. Ringwood: Viking.

Ring, I. \& Brown, N. (2002). Indigenous health: chronically inadequate responses to damning statistics. Medical Journal of Australia, 177, 629-631.

Ring, I. \& Brown, N. (2003). The health status of indigenous peoples and others. British Medical Journal, 327, 404-405.

Ring, I. \& Firman, D. (1998). Reducing indigenous mortality in Australia: Lessons from other countries. Medical Journal of Australia, 169, 528-533.
Royal Commission into Aboriginal Deaths in Custody (1991). Final report. Canberra: Australian Government Publishing Service.

Schmitt, L. H., Harrison, G. A., \& Spargo, R. M. (1998). Variation in epinephrine and cortisol excretion rates associated with behavior in an Australian Aboriginal community. American Journal of Physical Anthropology, 106(2), 249-253.

Schmitt, L. H., Harrison, G. A., \& Spargo, R. M. et al., (1995). Patterns of cortisol and adrenaline variation in Australian aboriginal communities of the Kimberley region. Journal of Biosocial Sciences 27(1), 107-116.

Schore, A. N. (1994). Affect regulation and the origin of the self: The neurobiology of emotional development. Hillsdale: Erlbaum.

Schore, A. N. (2003). Early relational trauma, disorganized attachment, and the development of a predisposition to violence. In M. F. Solomon \& D. J. Siegel (Eds.), Healing trauma: Attachment, mind, body, brain (pp. 107-167). New York: WW Norton.

Stanner, W. E. H. (1979). White man got no dreaming: Essays 1938-1973. Canberra: Australian National University Press.

Steenkamp, M. \& Harrison, J. (2001). Suicide and hospitalized self-harm in Australia. Canberra: Australian institute of Health and Welfare.

Swan, P. \& Raphael, B. (1995). Ways forward: National consultancy report on Aboriginal and Torres Strait Islander Mental bealth. Canberra: A.C.T., A.G.P.S.

Syme, S. L. (1997). Individual vs. community interventions in public health practice: Some thoughts about a new approach. Health Promotion Matters, 2 (July), 2-9.

Tatz, C. (1999). Genocide in Australia. Research discussion paper no. 8. Canberra: Australian Institute of Aboriginal and Torres Strait Islander Studies.

Tatz, C. (2001). Aboriginal suicide is different: A portrait of life and self-destruction. Canberra: Aboriginal Studies Press.

Trudgen, R. (2000). Why warriors lie down and die: Towards an understanding of why aboriginal people of arnhem land face the greatest crisis in health and education since European contact. Darwin: Aboriginal Resource and Development Services.

Tsey, K., Deemal, A. \& Whiteside, M., et al. (2003). It's an eye-opener for people to see you can change things: An evaluation of a "family wellbeing" personal and community development pilot project in two Cape York communities. Cairns: Apunipima Cape York Health Council and the University of Queensland. 
Tsey, K., Patterson, D. \& Whiteside, M., et al. (2004). A microanalysis of a participatory action research process with a rural Aboriginal men's health group. Australian Journal of Primary Health, 10(1), 64-71.

Westerman, T. (2003). Development of an inventory to assess the moderating effects of cultural resilience with Aboriginal youth at risk of depression, anxiety and suicidal behaviors. Unpublished PhD Thesis. Perth: Curtin University of Technology.
Zhao, Y., Guthridge, S., \& Magnus, A., et al. (2004). Burden of disease and injury in Aboriginal and non-Aboriginal populations in the Northern Territory. Medical Journal of Australia, 180 (17 May), 498-502.

Zubrick, S. R., Lawrence, D. M., \& Sillburn, S. R., et al. (2004). The Western Australian Aboriginal Child Health Survey: The bealth of Aboriginal children and young people. Perth: Telethon Institute for Child Health Research. 